\title{
Un policía preparado para todo Trazando nexos entre formación y práctica policial en la provincia de Santa Fe
}

\section{María Laura Bianciotto}

\author{
Investigaciones Socio-Históricas Regionales, Consejo Nacional de Investigaciones Científicas y Técnicas \\ (CONICET), Rosario, Argentina. \\ Universidad Nacional de Rosario, Facultad de Humanidades y Artes, Escuela de Antropología. Departa- \\ mento de Antropología Social, Rosario, Argentina. \\ Universidad Autónoma de Entre Ríos, Facultad de Humanidades, Artes y Ciencias Sociales. Paraná, Argentina \\ Correo electrónico: laurabianciotto@gmail.com
}

Recibido

enero de 2018

Aceptado

marzo de 2019

doi: 10.34096/cas.i5o.4076

Palabras clave

Formación; Experiencia formativa; Policía; Práctica; Filiación

\section{A police officer ready for anything. Establishing links between police training and practice in the province of Santa Fe}

\author{
Abstract \\ This paper is part of socio-anthropological research carried out between 2006 and 2012 \\ on police practices in Rosario City (Argentina). Within that framework, the investiga- \\ tion into the training process of future police agents turned out to be key to understand \\ concrete practices, knowledge, and values deeply rooted in the Police. We approach the \\ recruitment and training process in Santa Fe Police - Public security institute, ISEP- \\ in order to establish relationships between training process and practice; arguing that
}

\section{Key words}

Occupational training; Educational Experience; Police; Practice; Affiliation 
the transmission of the professional practice is essential during the training process, that is to say, knowledge related to abilities, skills and ways of proceeding. This allows us to discuss with different perspectives, as well as enable more complex analysis over profession and police practice.

\section{Um policial pronto para tudo. Traçando nexos entre a formação e a prática policial na província de Santa Fe}

\section{Resumo}

Palavras-chave

Formação; Experiência Formativa; Polícia; Prática; Filiação
1. Utilizamos la cursiva para referir a categorías y/o conceptualizaciones/expresiones propias del universo estudiado. Mantendremos el uso de las comillas dobles fundamentalmente para las citas textuales y las comillas simples para expresiones de índole coloquial.
Este trabalho é parte de uma pesquisa socio-antropológica que fizemos entre os anos 2006 e 2012 sobre a prática policial na Província de Santa Fe, Argentina, especificamente na cidade de Rosario. Neste marco, a indagação do processo de formação/instrução de futuros agentes policiais foi central para compreender as práticas concretas, os saberes e os valores atrelados fortemente à instituição. Seguindo esta linha abordamos o processo de recrutamento e formação da Polícia de Santa Fe —o ISeP, Instituto de segurança pública - com o intuito de de traçar algumas conexões entre a formação e a prática; sustentando que, no âmbito da formação, o que se coloca em jogo é essencialmente a transmissão de uma prática profissional, ou seja uma série de conhecimentos ligados a capacidades, habilidades e maneiras de proceder. Isto permitirá debater com outras perspectivas, assim como tornar complexas as visões no tocante ao ofício e a prática policial.

\section{Introducción}

Desde fines de los años ochenta y principios de la década del noventa, en América Latina se impone la necesidad de democratizar las fuerzas de seguridad, es decir, de adecuarlas al nuevo contexto sociopolítico que atraviesan nuestros países. Así, y frente al preocupante aumento de las tasas de delito, la puesta en marcha de una serie de reformas institucionales fueron vistas como una instancia imprescindible para llevar a cabo esta adecuación, ${ }^{1}$ fundamentalmente enfrentar el desafío de resolver el incremento de la delincuencia sin que ello implique un menoscabo de los derechos de los ciudadanos; reducir los índices de corrupción y violencia de los funcionarios policiales; como también superar la fuerte desconfianza de la ciudadanía hacia las fuerzas de seguridad. Todos estos aspectos conforman la denominada "seguridad ciudadana" (Frühling, 2002). Así entonces, la transformación requerida implicaba revisar las estructuras de funcionamiento y control de la actividad policial.

En esta dinámica, el proyecto y diagramación de dichas reformas tuvieron como pilares, las instancias de reclutamiento y formación de los futuros agentes policiales. Parte de esta centralidad se sostenía en un fuerte presupuesto: el de que existe una relación directa entre cambio educativo y transformaciones en las prácticas policiales. Así entonces, las modificaciones en planes de estudios (tales como la incorporación de temáticas en Derechos Humanos) y regímenes de reclutamiento (diferenciación respecto de la órbita militar-castrense) deberían tener un impacto en su práctica concreta (Frederic, 2014, 2016). En este sentido, las políticas impulsadas por los distintos gobiernos apuntan a esta instancia para lograr y demostrar transformaciones en la materia. 
Asimismo, reflexiones en esta línea llenan también los espacios de diarios y programas televisivos cuando toman estado público hechos de abusos y violencia policial; en ellos, la propuesta frente a estos casos se orienta a modificar la currícula para que esta incluya contenidos asociados con los valores democráticos (cumplimento de la ley, respeto por los derechos ciudadanos y libertades individuales, reconocimiento de las diversidades, etc.), lo que configura, muchas de las veces, una concepción de la práctica policial como un mero reflejo de la formación o capacitación.

En forma paralela, también puede rastrearse un supuesto básico en el seno de las instituciones policiales en el cual las experiencias de formación pierden valor y sentido a la luz de las experiencias concretas. Así, para numerosos agentes de policía 'lo importante' se ubica puertas afuera de las escuelas y centros de instrucción. ${ }^{2}$

En sintonía con este proceso, el campo académico también ha focalizado en el abordaje de la dimensión educativo-formativa de las fuerzas militares y de seguridad (Suárez de Garay, 2002; Hathazy, 2004; Bianciotto, 2007, 2009a, 2009b; Badaró, 2009; Sirimarco, 2009; Ugolini, 2010; Galvani, 2014; Lorenz, 2014; Frederic, 2016), atendiendo a su relevancia y pertinencia en tanto período por el que indefectiblemente los sujetos deben transitar para convertirse en agentes policiales o militares, pero sobre todo como instancia donde se incorporan e interiorizan rutinas, modos de proceder, de relacionarse y de hablar propios del universo policial. De este modo, las pesquisas sobre esta dimensión conllevan una reflexión sobre cuál es la injerencia que asume la educación/ formación policial en el marco de una configuración más amplia y compleja de la tarea policial. En otras palabras, poder mostrar cuáles son los niveles de vinculación entre ambas esferas: formación y práctica.

Sin embargo, algunos investigadores advierten sobre los peligros de homologar aquello que sucede en las escuelas e institutos con lo que efectivamente se lleva a cabo en la práctica concreta, y marcan así el riesgo de concebir un proceso rígido y, sobre todo, "desacertado a la hora de dar cuenta de las prácticas policiales efectivas" (Sirimarco, 2009, p. 23). Otras investigaciones denominan este tránsito como "reality shock", en tanto los policías lo experimentan como "un cambio importante, a veces radical, ente lo interiorizado y aprendido en la academia y la escenificación del mundo real policial. Entre lo dicho y lo que es" (Suárez de Garay, 2002, p. 199). De allí entonces, debemos señalar la precaución por no desestimar las dinámicas y aspectos propios que ambas instancias poseen; a riesgo de concebirlas como la causa-efecto de un mecanismo unilateralmente determinado y no como un proceso cuyas dimensiones - formación y práctica- se vinculan en una relación-tensión.

Vemos entonces que la educación/formación policial se presenta como un campo de investigación fructífero que nos permitirá conocer "puertas adentro" con base en qué aspectos y modalidades concretas pueden articularse la experiencia de la educación/ formación y la práctica propiamente dicha. Siguiendo esta línea, el presente trabajo se propone abordar y analizar una de las instancias de formación y socialización policial en la provincia de Santa Fe (Argentina); concretamente el Instituto de Seguridad Pública (ISeP), a partir de dos ejes principales: 1) el énfasis en la dimensión prácticoinstrumental de los saberes y la fuerte valoración de la experiencia; 2) el papel de la disciplina/jerarquía. A fin de situar estos núcleos de análisis es preciso realizar una breve referencia al proceso de investigación y a las características de la institución en la que nuestra pesquisa se llevó adelante.
2. Para el contexto local, una encuesta realizada a funcionarios policiales de Santa Fe (Equipo Delito y Sociedad UNL (Universidad Nacional del Litoral), 2008a y 2008 b) marca que seis de cada diez funcionarios consideran que el trabajo diario es el lugar más importante en la adquisición de los conocimientos; siendo solo uno de cada diez el que considera que lo son las escuelas de policía. Asimismo, en nuestra investigación hemos podido rastrear estas nociones en torno a la preocupación por la práctica futura de los cadetes. En este sentido, la idea fuerte que sostienen es que a ser policía se aprende en la calle. 


\section{Proceso de investigación y propuesta de análisis}

Desde el año 2006 iniciamos una investigación socioantropológica en torno a la práctica policial en la provincia de Santa Fe, particularmente en la ciudad de Rosario (Argentina). En ese marco, la indagación de la instancia de formación/instrucción de futuros agentes policiales resultó central para comprender prácticas concretas, saberes y valores fuertemente arraigados en la institución. Algunas de las preguntas iniciales de la pesquisa tales como: ¿qué significa ser policía?; ¿quiénes y por qué deciden ser policías?; ¿cuáles son los conocimientos, saberes y valores de los que se 'nutre' esta institución?, marcaron la relevancia y pertinencia de abordarla empíricamente. Así entonces, y a partir de un enfoque etnográfico (Sautu, 2003; Sautu, Boniolo, Dalle y Elbert, 2005; Achilli, 2005; Rockwell, 2009), indagamos en las rutinas y el organigrama institucional; nos relacionamos con cadetes, docentes e instructores; observamos clases y actividades de entrenamiento; relevamos programas y reglamentos; como también participamos en ceremonias y actos públicos. A partir de esta experiencia de investigación situada, observamos también los diferentes espacios físicos del instituto (salones, oficinas, patios, comedor, cuadras); registramos clases en asignaturas como Derecho Penal, Práctica Sumarial, el Taller de Prácticas Policiales y del área de entrenamiento, como Defensa Personal, Práctica de Tiro; también realizamos entrevistas a directivos, docentes e instructores; y mantuvimos numerosas charlas informales con cadetes. Todo ello fue triangulado con información periodística referida a novedades en el área policial (nuevos nombramientos, compra de equipamiento, entrevistas y declaraciones públicas de funcionarios); lectura y análisis de leyes, códigos y reglamentos. Pero sobre todas las cosas, nos propusimos permanecer la mayor cantidad de tiempo posible al interior de la institución, conocer sus rutinas, los movimientos del personal y cadetes, y asistir a eventos especiales como ceremonias, desfiles y actos.

Pues bien, ese tránsito también nos permitió observar los tiempos muertos; las ausencias; las tardanzas; las horas libres frente a docentes que — nuevamente- no iban a asistir; la falta de recursos básicos para el entrenamiento - como municiones y esposas-; así como los compromisos que la dirección del instituto asumía y superponía al cronograma de actividades ordinarias. En este conjunto, logramos también comprender que, si bien el ISeP era un espacio eminentemente policial, lejos estaba de ser conformado y atravesado solo por policías, sino que este ámbito de formación y entrenamiento se apoyaba en otros saberes e instituciones y, sobre todo, era atravesado por otras relaciones fuera de lo policial (ámbito judicial, relaciones con funcionarios políticos, militares, guardias de control civil, etcétera).

De allí que el interrogante por el sentido que asume este 'pasaje' por el instituto resulta el eje articulador de nuestra investigación y nos permite plantear como hipótesis que, en la instancia de educación/formación, lo que se pone en juego es fundamentalmente la transmisión de una práctica profesional, es decir, de una serie de conocimientos ligados a capacidades, habilidades, modos de actuar; esto es, un tipo de conocimiento ligado al saber hacer o "saber práctico" (Bourdieu, 2007).

Por ello, y para la Policía de Santa Fe, sostenemos que, más allá de los contenidos específicos desarrollados y la dinámica asumida, este proceso de educación/formación se propone estructurar la orientación hacia una manera de hacer las cosas. Entendemos que ello implica la apropiación de ciertos criterios, valoraciones, clasificaciones, modos de actuar y comportarse y, sobre todo, el reconocimiento de relaciones y modos de proceder. 


\section{Sobre el Instituto de Seguridad Pública: ¿nuevo paradigma de la formación policial?}

En el año 2004 se sancionó la Ley 12.333 que da creación al ISeP, ente autónomo de la esfera institucional policial, vinculado directamente con el actual Ministerio de Seguridad de la Provincia de Santa Fe. La creación de este instituto conlleva una reconfiguración de todas las instancias previas de formación policial en el territorio provincial, tanto la de los cuadros subalternos - suboficiales- como la de los cuadros superiores -oficiales y jefes-. A partir de ese momento, el ISeP coordina todas estas instancias que anteriormente se desarrollaban de manera separada. De allí que todo quedara contenido en un solo instituto y las anteriores direcciones quedasen agrupadas en la figura de un director general, quien es designado por el Poder Ejecutivo. ${ }^{3}$ Para el año 2007, el Poder Ejecutivo provincial inició el proceso de adecuación e implementación de la ley, por lo que en nuestra investigación tuvimos la oportunidad de observarlo y registrarlo, y esto nos permitió establecer algunas diferencias entre el "modelo tradicional" y el "modelo profesionalizante"4 (Varela, 2008), o escisión entre lo policialtradicional y lo civil-modernizante (Ugolini, 2010). A grandes rasgos, el paso de un modelo tradicional a uno profesional implica la "desmilitarización de la policía", esto es, la eliminación de desfiles, castigos y régimen de internado, como también la "equiparación de la formación policial con carreras de nivel terciario" (Ugolini, 2010, p. 306).

En sintonía con este proceso, el ISeP se propone una formación vinculada a la educación formal, por lo que, por medio del Ministerio de Educación, acredita dos carreras: la de Auxiliar en Seguridad y la de Técnico Superior en Seguridad. La primera de ellas tiene una duración de dos años; aquí los alumnos aún no poseen estado policial ${ }^{5} \mathrm{y}$, según las incumbencias establecidas, el título habilita a postularse al cuerpo policial, como así también a trabajar en el ámbito privado. ${ }^{6}$ La segunda carrera tiene una duración de un año y tiene como objetivo la especialización, enfocándose hacia la dirección de la administración institucional como a la conducción del personal. Todo ello implicó un proceso de escalafonamiento, de coordinación entre las diferentes áreas y de inclusión de un espacio psicopedagógico; en otras palabras, de adecuación a los lineamientos que rigen a otras instituciones educativas. Asimismo, estas modificaciones se articularon a nivel nacional, en el marco del Programa Nacional de Capacitación Policial (PRONACAP), cuyo eje central ha sido la elaboración de lineamientos generales en la formación de agentes policiales en Argentina, a fin de que cada fuerza de seguridad provincial pueda alcanzar estándares mínimos en esta área (Alonso y Garrote, 2009).

La entonces Directora General (DG) - una especialista en el área educativa- hablaba en el año 2007 de un proceso de "normalización", que implica también superar las resistencias que todo cambio acarrea.

Ahora bien, ¿qué lineamientos concretos se siguen con la nueva currícula? ¿Cuáles son sus contenidos específicos? En primer término, lo que se pretende es "profesionalizar la función policial”, y ello implica la actualización y especialización técnica en áreas como Defensa Personal, Mediación, Negociación, Práctica de Tiro, entre otras. Se espera que, bajo este fortalecimiento de prácticas específicas, los futuros policías realicen correctamente sus tareas, porque "cuando un hombre está más formado, menos posibilidades tiene de cometer errores" (DG, Rosario, diciembre de 2007). Otro de los aspectos en que se enfatiza es en el "tema valores": el compromiso y el respeto de las libertades ciudadanas y de los derechos humanos es un contenido que, según su directora, "impregna transversalmente toda la currícula”. Como tercer lineamiento se menciona el aspecto actitudinal y comunicacional como característico de este nuevo perfil:

Por dos cuestiones, la primera, las instituciones policiales han sido instituciones que por su carácter cerrado, la palabra no ha circulado, que esos diálogos [pausa
3. Si bien el director general es nombrado por el gobernador, surge de una terna de candidatos propuesta por un consejo interinstitucional y debe afrontar un concurso público.

4. Como parte de un proceso de investigación de mayor alcance, hemos realizado trabajo de campo en el ámbito de la educación policial desde el año 2001, en la entonces Escuela de Cadetes de Policía, que funcionaba en el edificio donde actualmente se encuentra el ISeP (sede Rosario).

5. Esta es una de las diferencias más relevantes con el modelo de formación policial anterior, ya que desde el momento en que ingresaban a la Escuela de Cadetes, los cadetes adquirían el estado policial; mientras que en la nueva propuesta educativa, los alumnos recién lo adquieren una vez que son incorporados a la fuerza policial.

6. Como señala Ugolini (2010), un $99 \%$ de los egresados solicita la inserción laboral en la Policía de Santa Fe. 
e interrumpe la frase] y que lo que no se saca [habla] implosiona [...] y además, porque podemos trabajar en la resolución de conflictos en la negociación. (DG, Rosario, diciembre de 2007)

De modo que - y en contraposición con las ideas de patriotismo, disciplina y jerarquía, vigentes en el modelo anterior- el nuevo proyecto del instituto se centra en la regulación de la dinámica educativa; es decir, en el ordenamiento de clases, programas y escalafonamiento de la planta docente. Esto apunta a un perfil de egresado asentado en la profesionalización y la especialización, lo que implica determinar incumbencias y competencias.

Sin lugar a dudas, todos estos lineamientos implican un cambio paradigmático respecto de cómo se afrontaba la educación/formación de agentes de seguridad y, como ya señalamos, va en sintonía con procesos sociales y políticos de mayor alcance. No obstante, debemos señalar que estas transformaciones - que nos permiten fijar un límite en 'lo nuevo' y 'lo viejo' - resultan sobre todo un recurso de análisis para situar cambios reglamentarios y legislativos, más que prácticas institucionales completamente diferenciadas. En este sentido, y como suele ocurrir en numerosos procesos de reformas institucionales, se presentan dificultades que obstaculizan la plena implementación del nuevo diseño curricular y que van desde el poco respaldo político (expresado en la falta presupuesto, recursos técnicos y logísticos), hasta las percepciones de los propios policías como intromisión inexperta y desinformada de las autoridades políticas (Ugolini, 2010).

De igual modo, y a los fines de este trabajo, esta breve presentación nos permite esbozar un marco de referencia para poder focalizar en lo que, a nuestro entender, conforman dos de los núcleos significativos que organizan y atraviesan este proceso de formación, y desde allí definirlo en términos de "experiencia formativa" (Rockwell, 1982).

En este sentido, la noción de experiencia se configura en un eje conceptual de suma relevancia en tanto "experiencia social" que recupera las construcciones, jerarquizaciones e interpretaciones de los propios actores sociales, no como elementos aislados, sino en la constante y dinámica tensión entre objetividad y subjetividad; sistema-actor (Troussel y Renzi, 2012). Así entonces, la noción de experiencia que nos interesa recuperar focaliza en el plano de las técnicas de medición, verificación y resolución de problemas que los actores llevan adelante en el curso de la vida social. Siguiendo esta idea, podremos ir describiendo y analizando los universos de sentido que los diferentes actores - directivos, alumnos, instructores, docentes - esgrimen frente a los interrogantes por la instancia de formación y su práctica futura.

\section{La práctica como herramienta, la experiencia como valor}

Mencionábamos previamente que el proceso de formación en la Policía de Santa Fe se inclina hacia un conocimiento práctico que resulta válido para transitar el afuera, la calle. Así, conocimientos específicos; codificaciones, normativas y procedimientos burocrático-administrativos resultan algunos de los aspectos más validados por los alumnos a la hora de apreciar las diferentes asignaturas; importancia siempre mediatizada por el horizonte del "después".

Cuestionario de elaboración propia de un total de cinco preguntas realizado a 17 cadetes de segundo año durante 2005. Total de varones, 8; mujeres, 9. Carácter voluntario y anónimo. No pretende constituir una muestra representativa, sino una aproximación a ciertas opiniones y valoraciones.
En un sucinto sondeo de opinión realizado a estudiantes del segundo año ${ }^{7}$ en torno a los contenidos y modalidades de enseñanza, estos destacaron mayormente las asignaturas de contenido jurídico, tales como Procesal Penal, Práctica Sumarial, Criminología, Derecho Contravencional, entre otras. Cuando inquirimos sobre las razones, aquellos que respondieron lo hicieron en este sentido: "porque está relacionado con lo policial, 
con lo que vas a tener que trabajar el día de mañana en la policía"; o bien "estas materias son nuestras guías para nuestro desenvolvimiento en la calle" (Cuestionario a cadetes, Rosario, mayo 2005).

De modo que, para los estudiantes, lo que se despliega en las clases es calibrado bajo el lente de su utilidad y pragmatismo. Si consideramos que muchas de las tareas policiales se vinculan al ámbito jurídico-administrativo, tales como la elaboración de actas, toma de denuncias, realización de peritajes y sumarios, esto permite comprender la fuerte inclinación a configurar el oficio policial; esto es, los quehaceres diarios y centrales de un agente de policía, sobre la base de una relación con el ámbito judicial y el derecho, en tanto expectativa de trabajo. Así, la importancia recae sobre todo en este círculo de asignaturas, hacia las que los estudiantes dirigen la mayoría de sus esfuerzos y preocupaciones.

Si bien otros autores han destacado ya el fuerte contenido jurídico-legal en el seno de la formación de policías argentinas y latinoamericanas (Frühling, 2002; Varela, 2008), nos interesa apuntar cómo, en el seno de la formación policial en Santa Fe, la percepción y valoración de los aspectos legales-procedimentales se direccionan claramente hacia un carácter instrumental, a la manera de una herramienta de trabajo. De modo que lo relevante en el seno policial será conocer reglas y codificaciones jurídicas no solamente para ordenar y orientar el trabajo - asociado mayormente a la prevención y represión del delito- sino también porque permite el propio resguardo; esto es, evitar inconvenientes que puedan implicarlos en hechos de incumplimiento o mal desempeño de las funciones. En este sentido, es contundente la justificación de una alumna: "[porque] muchas veces el empleado policial se defiende con los sumarios, como también algunas veces se hunde solo" (Alumna $2^{\circ}$ año, Rosario, mayo 2005).

Así, la valoración y validación por el saber práctico expresada por los cadetes se extenderá también a los modos en que se imparte la enseñanza; esto es, a la dinámica de las clases, como a la trayectoria del docente que la desarrolla. En relación con esto, las representaciones y ensayos, como la recepción de denuncias y operativos en los que se simula la toma de rehenes o simplemente una palpación frente a una detención resultarán situaciones muy apreciadas como dispositivo pedagógico a fin de poner en acto y afrontarlo en el futuro. Tal es el caso de las clases de Lengua, donde la docente vuelca los contenidos no solo para que conozcan de verbos y estructuras gramaticales, sino también para que ello pueda ser aplicado en la elaboración de Actas y Partes preventivos.

Significativamente, esta orientación no es solo pretendida por los cadetes, sino que los propios docentes e instructores consideran que ello es lo relevante al momento de llevar adelante la formación. Al respecto, los docentes desarrollarán las clases en torno a cuáles son los contenidos que consideran pertinentes que estos futuros agentes posean, asociados a criterios de actuación, modos de resolución y maneras de afrontar el hecho policial: "yo hago hincapié en la parte en la que ellos tienen actuación, porque nuestra materia es muy técnica, entonces trato de enfocar en lo que ellos van a hacer" (Docente de Derecho Procesal Penal, Rosario, septiembre 2005).

Siguiendo esta lógica, será entonces el relato de experiencias y casuística lo que permita introducir los contenidos que atraviesan las clases. Es interesante señalar cómo en esa articulación se van configurando nociones en torno al oficio policial, es decir, las incumbencias y destrezas que el agente de policía debe poseer. De modo que, no solo la enseñanza apunta a un qué hacer, sino también a un cómo proceder. En esta línea, el trabajo de Ugolini (2010) habla de una "artesanalidad" en el modo de transmisión de los saberes propios del oficio policial, y enfatiza en una "naturaleza fundamentalmente práctica y transmitida de los efectivos más experimentados a los novatos cadetes" (p. 312). 
8. Parte de estas reflexiones han sido vertidas en un trabajo que indaga la construcción de territorialidad/es a partir de prácticas policiales concretas y situadas (Bianciotto, 2018).
Ciertamente, lo señalado por el profesor Zaldívar, comisario mayor retirado a cargo del Taller de Prácticas Policiales, resulta acertado para profundizar sobre dichas cuestiones.

Amparado en su trayectoria, pero manteniendo un trato cordial y poco esquemático, el docente enfatiza particularmente en las ideas de "celeridad" y "diversidad". Constantemente repite: "recuerden, el policía tiene que resolver en un minuto lo que un abogado se toma tres meses, por eso hay que saber actuar rápidamente" (Registro clases taller Prácticas Policiales, Rosario, septiembre 2007). En este sentido, 'saber actuar' implica una capacidad de decisión y discernimiento en la vorágine del servicio, en la urgencia que los hechos demandan; de allí que también enfatiza en el control de las emociones y las actitudes. También, y a diferencia de un imaginario policial asociado estrictamente al delito y la punición; el profesor entiende que hay una multiplicidad de eventos y situaciones a los que el policía debe prestar atención y servicio; en tanto oficio conformado en y atravesado por el espacio público, la calle:

El policía es un personaje de la sociedad que tiene que saber un poquito de cada cosa desde... no sé, un ejercicio de resucitación cardiorrespiratoria hasta ayudar a una viejita a cruzar la calle o hasta tirotearse con un... con el peor de los delincuentes ¿no? Conocer la ley penal, o conocer la ley procesal, o bien entender lo que significan los derechos humanos pero a su vez tener el estado psíquico emocional como para no excederse ante una violación y muerte, por ejemplo, entonces la diversidad, el policía tiene que estar preparado para todo (énfasis nuestro). (Registro clases taller Prácticas Policiales, Rosario, septiembre 2007)

El vínculo estrecho entre Policía y espacio público ha sido profusamente desarrollado por diversos autores y disciplinas (Kant de Lima, 1999; Caimari, 2004; Tiscornia, 2004) que enfatizaron en el carácter [histórico] constitutivo de la necesidad de ordenar y vigilar "lo público" a fin de evitar sus males y desenfrenos; ocuparse de lo urbano, dirá Michel Foucault (2006). L'Huillet (2005) advierte que la propia genealogía del término policía - derivado del griego politeia [polis, ciudad]-, permite observar el proceso de tecnificación que este ha sufrido al reducirse su sentido más amplio, el "arte de procurar una vida cómoda y tranquila", por "el orden público de cada ciudad” (p. 3). Sin detenernos sobre este aspecto, notamos cómo la vida de la ciudad, sus ritmos y complejidades se convierten en actividad específica del oficio policial. $^{8}$

Por ello, "el policía está expuesto, permanentemente expuesto al peligro, a las vicisitudes de la vía pública” (Registro clases taller Prácticas Policiales, Rosario, septiembre 2007), señala el profesor Zaldívar. De allí entonces que lo importante resida sobre todo en reconocer "la incertidumbre", donde todo puede suceder: desde un leve accidente de tránsito en el que el agente presta asistencia a fin de evitar altercados, hasta la posibilidad de detectar un artefacto explosivo "frente a una sinagoga". Sobre este a priori el docente apela a presentar modalidades, poseer objetos y adquirir algunas rutinas a fin de contrarrestar el horizonte de posibles sucesos que los aguardarán frente a cada procedimiento. Por ejemplo, indica sobre un accidente de tránsito:

En un choque simple, el policía no tiene la obligación de intervenir, pero si somos vivos estamos uniformados expuestos en la vía pública y en presencia de testigos siempre tenemos que participar como funcionarios del Estado de lo que sucedió en la vía pública, aunque fuera un simple raspón entre dos autos [...] para que se pasen los datos, evitar riñas, evitar golpes, evitar escaramuzas o evitar que se metan terceros y además ver la posición en que quedaron los vehículos, las cercas golpeadas, las columnas, el semáforo caído, lo que fuere para evitar futuros, posibles, eventuales accidentes. De nuevo, no me dejen nunca la escena del hecho, no me dejen nunca en situación de que pueda correr peligro la población, una pérdida 
de gas, un cable cortado, entonces tengan especial atención a todo esto. (Registro clases taller Prácticas Policiales, Rosario, septiembre 2007)

Frente a esta configuración de la incerteza e imprevisibilidad, el profesor del taller enfatiza también en adquirir medidas de precaución, de alerta, que puedan evitar posibles riesgos y lesiones. Constantemente advierte:

\section{Rambo y la mujer maravilla están en Hollywood, acá entre mis alumnos no existe ni ningún Rambo ni ninguna chica maravilla, ni crean que son inmunes a las balas o que son inmunes a los cuchillazos [...] no quiero que nadie se exponga... más de lo necesario o innecesariamente ¿estamos? (Registro clases taller Prácticas Policiales, Rosario, septiembre 2007)}

El peligro puede presentarse en cualquier hecho; por tanto, estar alertas y no confiarse es central al momento de pensar la práctica futura.

Aunque distintas investigaciones han dado cuenta de que las situaciones de riesgo - esto es, en las que el agente policial corre peligro de muerte - son llamativamente poco frecuentes; vemos que esta percepción está fuertemente arraigada en la propia representación del oficio. Para el contexto de Francia, Dominique Monjardet (2003) señala que la autopercepción de los agentes de su actividad implica centralmente el mantenimiento del orden; aunque la mayoría de ellos realicen tareas relativas al tránsito o al espacio público en general.

En el contexto local, una encuesta señala que, si bien un $64,6 \%$ de los encuestados no usó su arma en ese año (2007) ni tampoco participó, en su carrera policial, de enfrentamientos que resultaron con personas heridas, ${ }^{9}$ las consideraciones en torno a los niveles de seguridad-inseguridad en que se realiza el trabajo marcan que más de la mitad de los consultados se sienten poco seguros, inseguros o muy inseguros y consideran que la posesión del arma es necesaria para cumplir su tarea (Equipo Delito y Sociedad, 2008a).

Vemos entonces, y sin apelar a un criterio de verdad-falsedad, que la percepción del riesgo y el peligro atraviesa la noción del oficio policial, muchas de las veces de forma independiente respecto de aquello que marcan las estadísticas. Estas nociones, articuladas a las de incerteza (dificultad de prever un mínimo de expectativas sobre lo que puede - o no- suceder) y a la multiplicidad de tareas, conforman el horizonte más inmediato del hacer policial. Sobre esta base, será entonces que la experiencia adquirida se convierte en un valor central, ya que enseña a actuar con celeridad. Estos señalamientos coinciden con lo expresado por otra investigación acerca de la formación policial en Santa Fe, la cual indica que la experiencia en la actividad práctica que poseen los instructores se configura como un valor agregado y validado en la transmisión de 'modos de ser y hacer', de proceder, en la que se combinan conocimientos teóricos y experiencias concretas, mediante la narración de hechos y también aconsejando sobre "las cosas cotidianas de la comisaría que hay que resolver" (Ugolini, 2010, p. 314).

\section{Sobre la dimensión disciplinaria y de obediencia al interior del ISeP}

Otro de los aspectos significativos que tuvimos en cuenta en el proceso de investigación fue el referido a la dimensión disciplinaria y de respeto a las jerarquías. Inicialmente, y como parte de una institución de tipo verticalista, entendíamos que la formación debía asentarse en un respeto irrestricto hacia los superiores, fundamentalmente en el trato protocolar; en la presencia de actividades de tipo castrense (tal como la utilización de movimientos vivos para sancionar algún tipo de inconducta); como también en el
9. Un $69,1 \%$ de los policías consultados nunca resultaron heridos. 
fuerte apego a una rutina de actividades en la que incondicionalmente debían acatarse horarios de clases, entrenamiento, descanso, etc. Parte de estas primeras nociones se cimentaron en la perspectiva de Michel Foucault — volcada particularmente en la obra Vigilar y castigar (1999) - y de todo el campo de estudios en torno a las instituciones de control social a partir de los conceptos de disciplina, poder y biopolítica, entre otros. Sin dejar de reconocer la importancia de su producción —en tanto es indiscutible la relevancia que ella ha tenido para situar y hacer visibles los ámbitos de encierro (prisiones, hospitales, orfanatos) como foco de análisis e investigaciones en la materia-, nuestra trayectoria de investigación en el ámbito de la formación policial nos marcó otras vías de indagación que nos permitieron problematizar estos supuestos iniciales.

Empíricamente esto se fue expresando en diversas instancias de la vida institucional, pero logramos observarlo con mayores detalles en particular en las actividades de entrenamiento específico - defensa personal, prácticas de tiro, traslado de detenido y uso de esposas, etcétera-. Así, en comparación con la socialización policial en las provincias de Córdoba o Buenos Aires, donde la rigidez, el dolor, la exigencia y sufrimiento corporal parecen constituir modalidades centrales en dicho proceso (Hathazy, 2004; Sirimarco, 2009), lo que sucede en el ISeP se aleja lo suficiente de estas experiencias para que pueda ser concebido como un proceso de instrucción del tipo disciplinar-castrense.

Ello se muestra claramente en dos aspectos: 1) el incumplimiento del cronograma; y 2) la dinámica que asumen las horas de preparación física de la llamada "Área de Cuerpo".

Sobre el primer aspecto, en numerosas instancias pudimos observar la falta de cumplimiento de las actividades establecidas por el cronograma y plan de estudios, sobre todo de las horas de clases y entrenamiento. En efecto, al interior de las aulas el registro de inasistencias resultaba amplio - entre ocho y diez ausentes sobre un total de veinticinco o treinta-, ya fuera por enfermedad de los cadetes o bien por estar afectado a algún servicio o tarea, tales como actos patrios, desfiles o comicios. En una de las visitas, una oficial reclamaba telefónicamente a un compañero de otra sección que "mande" a los cadetes a clase: "mirá, me lo dijo el subdirector delante de Serra, que los chicos vengan al aula, se me están quejando los profesores que no tienen alumnos en sus clases" (Registro № 38, Rosario, agosto 2007). Para el Área de Cuerpo, las distancias con lo diagramado en el cronograma son aún más claras, ya que las horas pautadas para la práctica de tiro y tácticas policiales son escasas y carecen de regularidad (aunque tengan un día y horario establecido en la rutina semanal). Entre las razones que pudimos relevar al respecto se encuentran la falta de municiones y armas en condiciones que permitan un correcto entrenamiento, como también que los instructores suelen cumplir, dentro del mismo horario, tareas administrativas.

En otra de las visitas pudimos observar claramente esta situación: luego de acordar con el Jefe "de Estudio" las clases a las que podríamos asistir, charlamos con el Jefe "de Cuerpo" para también coordinar las visitas en esa área. Este último nos comenta que ese día no hay mucha actividad ya que "al ser viernes los cadetes se están yendo a sus casas" (Charla Informal con Jefe de Cuerpo, Rosario, agosto 2007). Para él, los martes y jueves son los días con mayor actividad operacional. Así entonces, nos presentamos al martes siguiente para observar una clase de Defensa Personal y una Práctica de Tiro. Al llegar esa mañana la oficial que nos recibe nos comenta que la clase de Defensa Personal ya se había terminado y que no se sabía si se iba hacer la práctica de tiro. En este sentido, puede decirse que tanto cadetes como personal y docentes se acoplan a las novedades del día.

En efecto, no solo puede observarse que los "procesos de rutinización" (Giddens, 1995) presentes en el ISeP lejos están de ser un método disciplinar en el cual se ejerce un control minucioso en términos de "sujeción", "eficacia" y "docilidad" (Foucault, 1999); 
tampoco remiten a la programación estricta y vigilada de actividades dentro de una "institución total"; mucho menos a procesos de "mutilación del yo" (Goffman, 1984), sino que pueden asociarse con imágenes presentes en espacios públicos y civiles: las horas muertas, la carencia presupuestaria, los cambios imprevistos y las ausencias.

De todos modos, 'desajustes' de este tipo despiertan críticas y quejas de instructores y personal, asociadas a un mal funcionamiento de la institución, lo cual permite apelar a la necesidad de aplicar disciplina; es decir, de revisar las disposiciones y de reorientar la organización del ISeP según lineamientos de un pasado más o menos reciente. Esto nos muestra la vigencia que aún mantiene ese "deber ser" asentado en sentidos y valores que conforman el mundo policial.

En sintonía con ello, nuestros supuestos iniciales debieron ser revisados no solamente por el incumplimiento del cronograma, ${ }^{10}$ sino sobre todo porque las horas de preparación física son transitadas por la mayoría de los cadetes sin la rudeza y obediencia que otras investigaciones señalan (Hathazy, 2004; Sirimarco, 2009) y que incluso nuestras propias anticipaciones de sentido hacían suponer que allí encontraríamos. Así, por ejemplo, durante las clases de Defensa Personal, los cadetes muestran poca atención e interés por los contenidos ofrecidos y a las indicaciones del docente instructor; aun cuando las actividades impliquen el uso de "la tonfa" [cachiporra] o "la reducción y traslado de detenidos". En una de nuestras visitas observamos:

Hay 16 cadetes en la clase, dos son mujeres. Hay un grupo de 5 que se aparta del resto y conversan entre ellos. El clima es bastante relajado y muy similar a los que había registrado en situaciones anteriores; los cadetes hablan entre ellos, se ríen, juegan, otros dos se van. El docente va mostrando el ejercicio, algunos intentan practicarlo, otros solo observan [...] dos practican constantemente el ejercicio, otros hablan, algunos charlan y comentan el ejercicio. Realizarlo les provoca risa y se ponen a bromear y representar humorísticamente situaciones (Registro clase Defensa Personal, septiembre 2007).

El intercambio de bromas, al igual que la falta de atención y predisposición de los cadetes frente a docentes que 'negocian' la participación en la asignatura, permite visualizar la instancia del entrenamiento y la preparación física, no como experiencia de coerción y sometimiento. Sin embargo, con ello no pretendemos indicar que las actividades en estas asignaturas no resulten significativas dentro del proceso general de la formación, en tanto instancias de transmisión e intercambio de experiencias y anécdotas, de consejos y advertencias, usos del cuerpo y construcción de la corporalidad, etc.; aunque sí aparecen como subsidiarias - tanto en lo que observamos en las clases como en las valoraciones que los cadetes hicieron de ellas- de otras instancias más significativas. En este sentido, cabe problematizar una perspectiva que, influida básicamente por los trabajos de Foucault, ${ }^{11}$ concibe que el disciplinamiento y la sujeción de los cuerpos y sus voluntades resultan características inherentes a las instituciones de control social a fin de crear "cuerpos dóciles"; perspectiva hegemónica que por supuesto ha atravesado también este proceso de investigación (Bianciotto, 2008). ${ }^{12}$

Pero retomando el contrapunto antes planteado, lo que nos interesa remarcar es que este tipo de desajustes y acoplamientos, junto con los saberes más formalmente desarrollados en las clases, conforman el cotidiano del instituto y que, en términos concretos, van a permitir a los cadetes transitar la práctica futura, en tanto conocimiento y aprendizaje de coordenadas de actuación tales como: reorientar prioridades y urgencias según lo dispongan los superiores; cumplir otras tareas; alternar (y aprovechar) las horas muertas con jornadas de intensa actividad y valerse de los beneficios que establece la norma, como las licencias por carpeta médica. ${ }^{13}$
10. En numerosas visitas al ISeP pautadas de antemano, las clases y/o actividades previstas no se iban a realizar. Oportunamente, una de las instructoras del área operacional nos expresó “Mirá, nosotros cronograma tenemos, pero está de vista nomás" (Charla informal con docente del área de Cuerpo, Rosario, septiembre 2007).

11. Para una reflexión más profunda respecto de la influencia de la obra de Foucault, ver Caimari (2004, 2005).

12. Estos señalamientos permiten entonces reponer nuevamente la noción de "reflexividad" como aspecto clave en la investigación socioantropológica, en tanto el trabajo de campo nos abre hacia preguntas distintas de las que inicialmente formulamos a partir de los marcos o cuerpos teóricos (Guber, 1995). Ello supone ciertamente, "reconocer la dialéctica entre trabajo de campo y trabajo conceptual, desterrando así la posibilidad de reducir 'lo antropológico' a un método o a una concepción de la 'etnografía' como momento de descripción a-teórica de la investigación" (Achilli, 2005, p. 18).

13. La expresión nativa de "sacar carpeta”, refiere a una serie de artículos de la legislación policial que regulan las licencias por enfermedad, tanto física como psicológica. En muchos casos, las entrevistas y charlas con los cadetes e instructores expresaban claramente que estas licencias se utilizaban como recurso para prolongar algún descanso y/o que las ausencias no sean computadas como faltas. Sobre esta línea de análisis, el trabajo de Iván Galvani (2014) sobre los agentes penitenciarios de Buenos Aires problematiza la dicotomía entre obediencia/disciplinadesobediencia/indisciplina para comprender estas acciones en contextos específicos que posibiliten visualizar acciones intermedias. El autor lo hace a partir de la categoría nativa de "tener cintura", donde también se presentan situaciones vinculadas a las licencias médicas. 
Es por ello que hablamos de este proceso como "experiencia formativa", en tanto experiencia que subyace a la totalidad de las dimensiones que intervienen en el proceso del aprendizaje. Ciertamente, este concepto fue desarrollado para abordar las experiencias escolares iniciales - atendiendo a un proceso que articula una serie de prácticas y relaciones institucionalizadas e históricas, junto con variaciones regionales, decisiones políticas, prácticas cotidianas, etc.- (Rocwell, 1982); lo que permite un replanteamiento de la idea de socialización como simple "interiorización" para situarlo en términos de "apropiación"; esto es, mostrar la relación activa que se establece entre un sujeto particular y la multiplicidad de recursos y prácticas culturales que caracterizan la vida cotidiana (aquí especialmente las experiencias escolares) (Padawer, 2010). Si bien lo recuperamos en un marco de educación diferente, esta noción nos posibilita mostrar una experiencia de formación que resulta flexible y dinámica, a la vez que nos marca la distancia con un proceso esquemático y preestablecido.

De allí que la validez y pertinencia del pasaje por el ISeP no resida estrictamente en adquirir ciertos contenidos curriculares sino, sobre todas las cosas, en experimentar las dinámicas, ordenamientos, criterios, etc., sobre los que ese currículum se asienta. Como señala Cristian Varela (2008) en torno de los sistemas educativos policiales del noreste argentino y de los cuerpos policiales federales: "más y antes de lo que se traza en la pizarra del aula, lo que efectivamente forma al enseñado es la organización en su conjunto, con sus prácticas y relaciones materiales y efectivas" (p. 65).

\section{Palabras finales}

En este trabajo nos propusimos abordar la instancia de reclutamiento y formación de la Policía de Santa Fe - ISeP- con el objetivo de poder trazar algunos nexos interpretativos entre formación y práctica policial. A partir de un enfoque etnográfico y dentro de una investigación socioantropológica, describimos y analizamos dos de los núcleos que, en nuestra investigación, resultaron de lo más relevantes para comprender dicho proceso de formación: práctica/experiencia y jerarquía/disciplina. A partir de la descripción y análisis de ambos ejes, pudimos, inicialmente, destacar la relevancia y pertinencia de investigar esta primera instancia de socialización policial como aspecto clave en el examen del campo de la seguridad y de los actores que allí intervienen políticos, funcionarios de gobierno, policías, periodistas, especialistas, entre otros-. En este mismo sentido, la referencia y el diálogo con otras investigaciones apuntan a marcar la diversidad y complejidad dentro de las instancias de capacitación y formación de las fuerzas de seguridad en nuestro país; para abonar así a lecturas alejadas de perspectivas homogeneizantes de estas instituciones y sus agentes.

En términos concretos, y como contrapunto de la mirada policial que concibe que el aprendizaje se da en la calle (y por tanto que en las escuelas no se aprende nada útil), nuestra investigación nos ha permitido argumentar que "el pasaje" por el ISeP no resulta una instancia escindida de la práctica policial propiamente dicha; sino que nos permite rastrear algunas filiaciones referidas a los sentidos del oficio policial, valores, maneras de relacionarse, vínculos presentes, etc., que nos acercan al entramado en que arraigan la propia institución y sus prácticas. Siguiendo esta línea, recalamos en el valor de la experiencia policial, de las anécdotas, relatos, consejos, de las maneras posibles de proceder, cómo hablar, qué decir (y qué no); del énfasis en la incertidumbre para definir la propia labor, y con ella las nociones de peligro, precaución y riesgo. En este marco, y teniendo la posibilidad de acceder en varias etapas a la institución y de conocer a sus miembros - directivos, docentes, cadetes, oficiales e instructores-, logramos un abordaje más afín y acorde con el ámbito de su espacio-tiempo, donde el disciplinamiento y la severidad en el trato daban paso a situaciones ligadas a lo recreativo y donde los cadetes realizaban actividades alejadas de lo constrictivo o extenuante, sino 
que se alternaba con momentos de participación y atención a la consigna con otros de dispersión, charla e incluso evasión, cuando no de total ausencia.

De este modo, la investigación nos permitió comenzar a problematizar los supuestos iniciales en torno a un proceso de formación asentado en una disciplina fuertemente acatada, con énfasis en el respeto por la jerarquía y con un sentido de fuerte verticalismo, para entender el ordenamiento de las tareas y actividades con otras herramientas de análisis. Bajo esa impronta, la categoría de experiencia formativa posibilitó la convergencia de estos diferentes elementos y situaciones que desbordan las diagramaciones curriculares y las disposiciones institucionales, y nos permitió visibilizar aspectos de la rutina y cotidianeidad institucional.

Se suma, de este modo, un espectro de indagación y análisis sobre estos espacios de formación y, fundamentalmente de la potencialidad de seguir examinando en la conexión con la práctica policial futura. Esperamos que estos lineamientos resulten un genuino aporte que se traduzca, a su vez, en nuevos interrogantes de investigación, a fin de seguir profundizando y afianzando el campo problemático. ${ }^{14}$

\section{Sobre la autora}

Doctora en Humanidades y Artes (mención Antropología) por la Universidad Nacional de Rosario. Profesora Adjunta (reemplazante) en la Facultad de Humanidades y Artes (UNR). Auxiliar de primera categoría (ordinaria) en la Facultad de Humanidades, Artes y Ciencias Sociales UADER. Becaria posdoctoral (CONICET/Investigaciones SocioHistóricas Regionales) Rosario, Argentina.
14. La creación de nuevas policías "de proximidad" (por ejemplo, la Policía Comunitaria) o de cuerpos especializados (como la Policía de Investigaciones) e incluso las numerosas policías municipales creadas en Buenos Aires durante la gestión de Daniel Scioli como gobernador, conforman un interesante abanico de posibles líneas de trabajo e investigación en el área. 


\section{Q Referencias bibliográficas}

»Achilli, E. (2005). Investigar en antropología social. Los desafíos de transmitir un oficio, Rosario: Laborde editor.

»Alonso, J. y Garrote, E. (2009). Reflexiones y conceptos en torno a las políticas de formación policial de la República Argentina. Cuadernos de Seguridad, 11, 209-225.

» Badaró, M. (2009). Militares o ciudadanos. La formación de los oficiales del Ejército Argentino, Buenos Aires: Prometeo.

» Bianciotto, Ma. L. (2007). Formación y Práctica Policial en Argentina: nuevas perspectivas de análisis desde la categoría de profesión. Actas del VII RAM, 23 al 26 de julio, Porto Alegre, Brasil.

» Bianciotto, Ma. L. (2008). La pertinencia disciplinar en el abordaje de la institución policial: reflexiones y revisiones desde la propia experiencia de investigación. Revista de la Escuela de Antropología, XIV, 111-120.

» Bianciotto, Ma. L. (2009a). Tres aspectos para pensar el proceso de formación profesional en la Escuela de Cadetes de la Policía de Santa Fe. Delito y Sociedad, 27(18), 85-95.

» Bianciotto, Ma. L. (2009b). Práctica y formación policial en Santa Fe: algunos aspectos para pensar su vinculación. Actas del X Congreso Nacional de Sociología Jurídica, 12 al 15 de noviembre, Córdoba, Argentina.

» Bianciotto, Ma. L. (2018). Prácticas policiales y construcción de territorialidad/es en la ciudad de Rosario (Santa Fe, Argentina). Aportes desde una investigación socio-antropológica. Estudios Socioterritoriales, 24 (julio-diciembre), eo07. Recuperado de: http:// www.fch.unicen.edu.ar/ojs-3.1.o/index.php/estudios-socioterritoriales/article/view/238

» Bourdieu, P. (2007). El sentido práctico. Buenos Aires: Siglo XXI.

»Caimari, L. (2004). Apenas un delincuente. Crimen, castigo y cultura en la Argentina, 18801955. Buenos Aires: Siglo XXI.

» Caimari, L. (2005). Usos de Foucault en la investigación histórica. Documento de Trabajo nº39, UDESA. Recuperado de: http://repositorio.udesa.edu.ar/jspui/handle/10908/446

»Equipo Delito y Sociedad (2008a). Violencia Policial en la Provincia de Santa Fe 1998/2006. Informe General. Santa Fe: Universidad Nacional del Litoral.

"Equipo Delito y Sociedad (2008b). Experiencias, representaciones y opiniones de los policías de la provincia de Santa Fe. Primer informe de la encuesta policial 200. Santa Fe: Universidad Nacional del Litoral.

» Foucault, M. (1999). Vigilar y Castigar. Buenos Aires: Siglo XXI.

» Foucault, M. (2006). Seguridad, territorio, población. Ciudad de México: Fondo de Cultura Económica.

» Frederic, S. (2014). La formación policial en cuestión: impugnación, valoración y transmisión de los ‘saber hacer’ policiales. En S. Frederic, M. Galvani, J. Garriga Zucal y B. Renoldi (Eds.), De Armas Llevar. Estudios socioantropológicos de los quehaceres de policías y de las fuerzas de seguridad (pp. 271-302). La Plata: Universidad Nacional de La Plata.

» Frederic, S. (Coord.) (2016). De la desmilitarización a la profesionalización. Un estudio etnográfico sobre la formación básica de la Policía Federal Argentina. Bernal: Universidad Nacional de Quilmes. Recuperado de: http://unidaddepublicaciones.web.unq.edu.ar/ wp-content/uploads/sites/46/2018/o4/e-book-DelaDesmilitarizacionalaProfesionalizacion-Frederic.pdf 
» Frühling, H. (2002). La reforma policial y el proceso de democratización en América Latina. Santiago de Chile: Centro de Estudios para el Desarrollo.

» Galvani, I. (2014). Cuestión de 'cintura'. Formas de obedecer y desobedecer en el personal subalterno del Servicio Penitenciario Bonaerense. En S. Frederic, M. Galvani, J. Garriga Zucal y B. Renoldi (Eds.), De Armas Llevar. Estudios socioantropológicos de los quehaceres de policías y de las fuerzas de seguridad (pp. 115-145). La Plata: Universidad Nacional de La Plata.

» Giddens, A. (1995). La constitución de la sociedad. Bases para una teoría de la estructuración. Buenos Aires: Amorrortu.

" Goffman, E. (1984). Internados: ensayos sobre la situación social de los enfermos mentales. Buenos Aires: Amorrortu.

» Guber, R. ([1995] 2004). El salvaje metropolitano. Reconstrucción del conocimiento social en el trabajo de campo. Buenos Aires: Paidós.

» Hathazy, P. (2004). Cosmologías del desorden: el sacrificio de los agentes antidisturbios y el sentido de su violencia. Actas del VII Congreso Argentino de Antropología Social, 25 al 28 de mayo. Villa Giardino, Córdoba, Argentina.

» Kant de Lima, R. (1999). Policía, Justicia e Sociedades no Brasil. Uma abordagem comparativa dos modelos de administraçao de conflitos no espaço publico, Sociologia Politica, 13, 23-38.

» L' Huillet, H. (2005). La Genealogie de la Police. Culture y Conflits, 48, 1-18. Recuperado de: https://journals.openedition.org/conflits/907\#citedby

» Lorenz, M. (2014). Enseñar a tirar. Aprender a morir. En S. Frederic, M. Galvani, J. Garriga Zucal y B. Renoldi (Eds.), De Armas Llevar. Estudios socio antropológicos de los quehaceres de policías y de las fuerzas de seguridad (pp. 173-208). La Plata: Universidad Nacional de La Plata.

» Monjardet, D. (2003). O que faz a polícia. Sociologia da força pública. San Pablo: Editora da Universidade de São Paulo (EDUSP).

»Padawer, A. (2010). Tiempo de estudiar, tiempo de trabajar: la conceptualización de la infancia y la participación de los niños en la vida productiva como experiencia formativa. Horizontes Antropológicos, 34, 349-375.

» Rockwell, E. (1982). De huellas. Bardas y veredas. Una historia cotidiana en la escuela. Ciudad de México: Centro de Investigación de Estudios Avanzados-IPN.

"Rockwell, E. (2009). La experiencia etnográfica. Historia y cultura en los procesos educativos. Buenos Aires: Paidós.

»Sautu, R. (2003). Todo es teoría. Objetivos y métodos de investigación. Buenos Aires: Lumiere.

»Sautu, R., Boniolo, P., Dalle P. y Elbert R. (2005). Manual de Metodología. Buenos Aires: Consejo Latinoamericano de Ciencias Sociales (CLACSO).

»Sirimarco, M. (2009). De civil a policía. Una etnografía del proceso de incorporación a la institución policial. Buenos Aires: Teseo.

»Suárez de Garay, Ma. E. (2002). De estómago, de cabeza y de corazón. Un acercamiento antropológico a los mundos de vida de los policías en Guadalajara, México (tesis de doctorado). Universidad Autónoma de Barcelona, Barcelona, España.

» Tiscornia, S. (2004). Entre el imperio del Estado de Policía y los límites del derecho, Nueva Sociedad, 191 (mayo-junio), 78-89.

» Troussel, L. y Renzi, M. (2012). La noción de experiencia en la investigación sobre formación y trabajo docente. Interrogantes epistemológicos. Educaçao e Políticas em debate, $2,35-52$. 
" Ugolini, A. (2010). Vieja y nueva artesanalidad en la formación policial de la provincia de Santa Fe. En S. Frederic, O. Graciano y G. Soprano (Coords.), El estado argentino y las profesiones liberales, académicas y armadas (pp. 303-330). Rosario: Prohistoria.

»Varela, C. (Coord.) (2008). La educación policial. Estudio de los sistemas educativos policiales de la Región NEA y de las fuerzas de seguridad y cuerpos policiales federales. Secretaría Seguridad del Interior, Programa de las Naciones Unidas para el Desarrollo (PNUD): Buenos Aires. 